\title{
Application of Strength Requirements to Complex Loading Scenarios
}

\author{
Scott England ${ }^{1}$, Sudhakar Rajulu ${ }^{2}$ \\ ${ }^{1}$ MEI Technologies Inc. \\ 2525 Bay Area Blvd. Suite 300 \\ Houston, TX 77058, USA \\ ${ }^{2}$ NASA Johnson Space Center \\ 2101 NASA Parkway \\ Houston, TX 77058, USA
}

\begin{abstract}
NASA's endeavors in human spaceflight rely on extensive volumes of human-systems integration requirements to ensure mission success. These requirements protect for space hardware accommodation for the full range of potential crewmembers, but cannot cover every possible action and contingency in detail. This study was undertaken in response to questions from various strength requirement users who were unclear how to apply idealized strength requirements that did not map well to the complex loading scenarios that crewmembers would encounter. Three of the most commonly occurring questions from stakeholders were selected to be investigated with human testing and human modeling. Preliminary findings indicate deviation from nominal postures can affect strength requirement compliance positively or negatively, depending on the nature of the deviation. Human modeling offers some avenues for quickly addressing requirement verification questions, but is limited by the fidelity of the model and environment.
\end{abstract}

Keywords: NASA $\cdot$ Strength $\cdot$ Requirements $\cdot$ Biomechanics $\cdot$ Ergonomics · Human-Systems Integration $\cdot$ Spacesuits

\section{Introduction}

NASA programs involving human spaceflight usually design operations and hardware around human performance capabilities. In general, these capabilities are defined to protect for task completion by the majority of potential crewmembers, who may be weak, injured, or deconditioned by extended time in microgravity. Currently the primary references for questions regarding crew strength abilities are the strength tables in present in the various program level requirements documents including the Human Systems Integration Requirements [1] and the ISS Crew Transportation and Services Requirements Document [2]. These tables present 34 uniaxial exertions for the whole body. Table 1 illustrates the format of typical NASA strength requirement tables. These 
tables are repeated for each suit configuration, typically unsuited, suited-unpressized, and suited pressurized. Unfortunately, tasks required of crewmembers are not always easily represented as an isometric exertion in a single direction.

Table 1. Example of idealized strength exertions from typical NASA strength requirements

\begin{tabular}{|c|c|c|c|c|c|}
\hline \multicolumn{2}{|c|}{ Type Of Strength } & \multicolumn{3}{|c|}{$\begin{array}{l}\text { Minimum Crew Operation Loads } \\
(\mathrm{N}(\mathrm{Lbf}))\end{array}$} & \multirow{2}{*}{$\begin{array}{l}\text { Maximum } \\
\text { Crew } \\
\text { Operational } \\
\text { Loads } \\
\text { (N(Lbf)) }\end{array}$} \\
\hline & & $\begin{array}{c}\text { Crit } 1 \\
\text { Operations }\end{array}$ & $\begin{array}{c}\text { Crit } 2 \\
\text { Operations }\end{array}$ & $\begin{array}{c}\text { Other } \\
\text { Operations }\end{array}$ & \\
\hline \multicolumn{2}{|c|}{ One Handed Pulls } & \multicolumn{4}{|c|}{ One Handed Pulls } \\
\hline $\begin{array}{l}\text { Seated Horizontal } \\
\text { Pull In } \\
\text { [Subject in a seated } \\
\text { position pulls } \\
\text { towards his/her } \\
\text { body. } \\
\text { Unilateral/Isometric } \\
\text { measurement] }\end{array}$ & & $111(25)$ & $147(33)$ & $276(62)$ & $449(101)$ \\
\hline $\begin{array}{l}\text { Seated Vertical Pull } \\
\text { Down }{ }^{2} \\
\text { [Subject in a seated } \\
\text { position pulls } \\
\text { downwards. } \\
\text { Unilateral/lsometric } \\
\text { measurement] }\end{array}$ & & $125(28)$ & 165 (37) & $311(70)$ & 587 (132) \\
\hline
\end{tabular}

The Anthropometry and Biomechanics Facility (ABF) maintains Subject Matter Expert (SME) status over NASA's strength requirements and frequently fields questions regarding how to interpret and apply the strength requirements. These questions usually focus on one or more of several confounding factors that are often encountered when mapping uniaxial exertions to functional tasks. These include:

- How to handle multiple joint exertions?

- How to deal with a subject bracing against their environment?

- How to interpret off-nominal exertions?

Potential solutions include task modification, biomechanical analyses, modeling, and human strength testing. This study sought to improve the utility of existing strength requirements by providing a consistent response for dealing with situations containing complex loading scenarios and begin laying the groundwork for more comprehensive strength requirements in the future. Phase I of this study investigated differences in strength performance between nominal and complex loading scenarios with human subjects and with human models. Phase II will build upon lessons learned from Phase I and expand to include suited testing and additional loading scenarios.

The foundation of strength requirements applied to human spaceflight are the 34 strength exertions presented in the primary program-level requirements documents, the HSIR and the ICTSR. These 34 exertions, while extensive, are not fully comprehensive of all possible exertions that could be expected of a crewmember in the completion of mission objectives. This study documents the process of how strength requirements should be used and what to do when a task does not easily fall under the supplied strength requirements. 


\section{$2 \quad$ Method}

Stakeholders and users of NASA's strength requirements were polled regarding commonly occurring issues in mapping tasks from NASA missions and hardware development to strength requirements provided in the program human factors requirements documents. Feedback from strength requirement users could be generalized into three major categories, including:

1. How does one combine multiple-joint exertions?

2. How does one deal with braced exertions?

3. How does one deal with off-nominal position exertions?

\subsection{Test Scenarios and Setup}

The applications of these confounding factors were diverse, potentially expanding to include any exertion or combination of exertions from the strength requirement tables. Several down-selection criteria were deployed in order to constrain the problem further, including criticality of the task, frequency of the task, and ability of the task to be replicated in a $1-\mathrm{g}$ environment. Specific tasks were chosen and reconstructed in a biomechanics laboratory environment as well as in a commercially available strength-modeling package, 3D Static Strength Predictor Program (3DSSPP). 3DSSPP was developed at the Center for Ergonomics at the University of Michigan for the purpose of predicting static strength capabilities by various aspects of the population [3]. An initial run of two unsuited pilot subjects was conducted to verify the test technique in Phase I of this study before a later full run of six to eight suited tests subjects in Phase II.

\subsubsection{Multiple-Joint Exertions}

A multiple-joint exertion involves situations where a control is operated with a combination of two joints, for example, concurrent motion of the elbow and wrist (Figure 1). This situation may arise when a seated crewmember needs to perform a maximal reach from a restrained position in order to actuate a piece of hardware. Here either the wrist or the elbow could be flexed to actuate the hardware. Primary questions involve which type of exertion to use and can more than one exertion be added together simultaneously.

Human strength data was collected by positioning the head of the PrimusRS at a height even with the subject's shoulder and installing a handle attachment to measure a vertical force. Subjects were instructed to grip the Primus attachment with the shoulder flexed to 90 degrees and elbow straight while applying a maximal exertion in the upward vertical direction with just the wrist in one set of trials and just the elbow in another. Each set was repeated three times or until the coefficient of variation was below $10 \%$ for three trials. This test setup was modeled in 3DSSPP by placing the simulated subject in the same posture as the human subjects and applying a load to the center of the right hand. The model does not possess the option of selecting which muscle set to activate, so the load at the hand was set to the wrist flexion strength requirement load 
of $17 \mathrm{lbs}$. in one run, and the elbow flexion strength requirement load of $8 \mathrm{lbs}$. in another. This setup was run with models possessing $50^{\text {th }}$ percentile male, $95^{\text {th }}$ percentile male, and $5^{\text {th }}$ percentile female anthropometries.

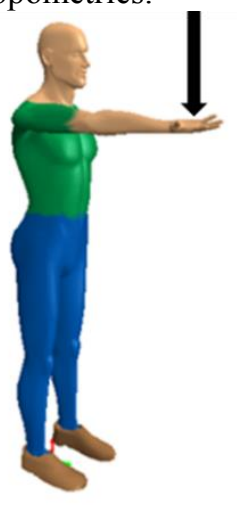

Figure 1. Multi-joint exertion of wrist and elbow

\subsubsection{Braced Exertions}

Braced exertions involve a confounding factor where only one arm may be used to actuate the hardware of interest, but the second arm is available for bracing, as illustrated in Figure 2. While not present in the 34 exertions from the NASA strength tables, this is potentially a desirable approach to increase the ability of the free arm to react opposite to the bracing.
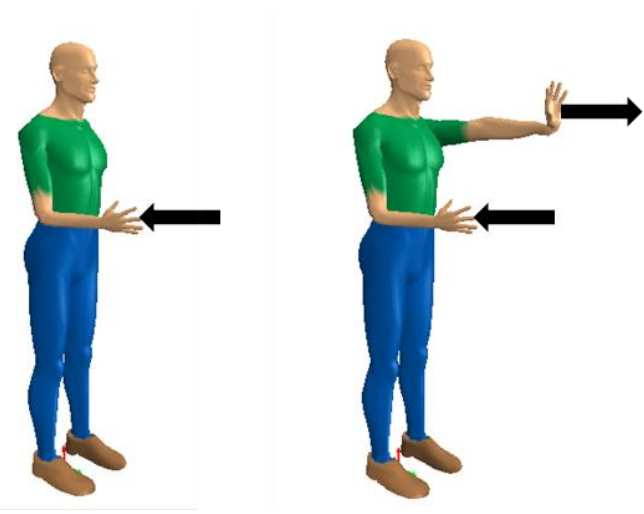

Figure 2. Unbraced vs. Braced Exertions

Human strength data was collected in this posture by positioning the PrimusRS such that force could be exerted into the long axis of the forearm with the subject's elbows bent to 90 degrees of flexion. Maximal exertions of horizontal force were collected with the subject in each of two postures. These postures included an unbraced stance, supported by only the soles of their feet and the grip of their dominant hand, and a braced stance where the subject's non-dominant arm could firmly react against a rigid, an- 
chored surface. This test setup was modeled in 3DSSPP by placing the simulated subject in the postures shown in Figure 2 and applying a load to the center of the right hand and left hands. The load in the right hand was the arm pull strength requirement load of $24 \mathrm{lbs}$. For braced exertions, the left hand received the arm push strength requirement load of $22 \mathrm{lbs}$. This setup was run with models possessing $50^{\text {th }}$ percentile male, $95^{\text {th }}$ percentile male, and $5^{\text {th }}$ percentile female anthropometries.

\subsubsection{Off-Nominal Exertions}

Off-nominal exertions involve a situation where a piece of hardware requires rotational motion that must be decomposed into simpler, unidirectional motions (Figure 3). Additionally, these motions may be required to take place outside of the nominal posture presented in the strength tables.

Figure 3. Off-Nominal Exertions
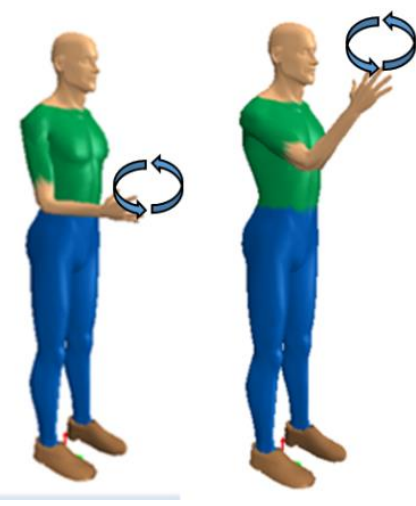

Human strength data was collected in this posture by positioning the PrimusRS such that the subject's dominant hand could grasp the handle attachment of the dynamometer with the elbow flexed to 90 degrees for the nominal position and with the handle at approximately eye-level for the off-nominal position. Subjects performed four maximal exertions in each posture: pushing away, pulling toward, pulling medially, and pulling laterally. These four maximal exertions were performed in both the nominal and offnominal posture. This test setup was modeled in 3DSSPP by placing the simulated subject in the postures shown in Figure 3 and applying a load to the center of the right hand. The load in the right hand was iterated through the strength requirement load corresponding to a push load of $22 \mathrm{lbs}$., a pull load of $24 \mathrm{lbs}$., a medial load of $13 \mathrm{lbs}$., and a lateral load of $8 \mathrm{lbs}$. This setup was run with models possessing $50^{\text {th }}$ percentile male, $95^{\text {th }}$ percentile male, and $5^{\text {th }}$ percentile female anthropometries.

\subsection{Unsuited Human Strength Testing}

Human data was collected using a PrimusRS (BTE Technologies, Hanover, Maryland) strength dynamometer setup to simulate the problematic tasks to the greatest degree 
possible. Human strength data was collected using the Caldwell method [4]. The core concepts of this method include:

- Strength is assessed with a steady exertion sustained for four seconds

- Effort should be gradually and steadily increased to maximum without jerking within approximately one second

- No instantaneous feedback is provided to the subject during testing

- No goal setting, rewards, nor competition is permitted during testing

- A minimum of one minute rest is provided between trials

One-handed tasks were completed with the subject's dominant hand alone. Each task was repeated at least three times with the coefficient of variance (COV) calculated after three repetitions. Whenever the COV was above $10 \%$, additional repetitions were completed until three exertions have a COV below $10 \%$. Pilot testing was completed with two unsuited subjects to verify the test setup and identify issues not immediately obvious from human strength modeling. Full human testing will be completed with suited and unsuited subjects early in Phase II of the study in 2016.

\subsection{Human Strength Modeling}

Human strength modeling was performed using 3D Static Strength Predictor Program (3DSSPP). Its primary output involves presenting the percentage of the population capable of completing an input task, based upon the NIOSH lifting equation $[3,5]$ and empirical calculations on population strength. As such, it is not actually capable of definitively saying whether a task could be completed for a single actuation. Rather, 3DSSPP provides feedback regarding what percentage of the population is capable of generating the required moments to resist the input forces, and if this task could be completed for 8 hours without elevated risk of injury. It is fair to estimate, however, that if a task could be safely completed regularly for a duration of 8 hours, a weak subject could complete it a single time. It is important to note that human modeling should not be used alone in determining success of task completion. The input capabilities of 3DSSPP are somewhat limited, so not all possible human capabilities are available within the software.

The primary results of interest from 3DSSPP are the strength percent capable calculations. The joint moments necessary to solve the modeled setup statically are calculated and compared to an equation for distribution of population strength. The percentage of the population with the capability to generate loads greater than the required loads is then reported. The population strength capabilities are determined from empirical mean strength equations developed from numerous sources and documented in relevant literature.

\section{$3 \quad$ Results \& Discussion}

Results of human strength testing and human strength modeling are presented and analyzed below. They are paired by task being completed to highlight the differences between modeling and human testing. Human strength testing values are presented in 
pounds-force, which can be directly compared to the strength requirement value for the task being simulated. Human modeling results are presented in terms of the percent of the population accommodated at each relevant joint. That is to say, the percent of the population possessing the strength to successfully complete the task being modeled. These percentages are determined through a combination of subject anthropometry and the output of the biomechanical models utilized by 3DSSPP.

\subsection{Multiple Joint Exertion}

Results from the multiple joint exertion analysis are presented in Table 2. Percentages of the population possessing the strength capable to successfully complete the task are presented on the right side of the table. The average loads across test subjects are in the bottom rows of the tables, as labeled.

Table 2. Multiple Joint Exertion Results

\begin{tabular}{|c|c|c|c|c|c|c|}
\hline \multirow[b]{2}{*}{ Subject } & \multirow[b]{2}{*}{ Hand Load Source } & \multirow{2}{*}{$\begin{array}{c}\text { Load at } \\
\text { Hand } \\
\text { (lbs) }\end{array}$} & \multirow{2}{*}{$\begin{array}{c}\text { Minimum \% } \\
\text { Accommodated }\end{array}$} & \multicolumn{3}{|c|}{$\%$ Accommodated at } \\
\hline & & & & Shoulder & Elbow & Wrist \\
\hline \multirow{2}{*}{$\begin{array}{c}\text { 50th Percentile } \\
\text { Male Model }\end{array}$} & Wrist Flex Requirement Load & 17 & $82 \%$ & $86 \%$ & $97 \%$ & $82 \%$ \\
\hline & Elbow Flex Requirement Load & 8 & $98 \%$ & $99 \%$ & $100 \%$ & $98 \%$ \\
\hline \multirow{2}{*}{$\begin{array}{c}\text { 95th Percentile } \\
\text { Male Model }\end{array}$} & Wrist Flex Requirement Load & 17 & $69 \%$ & $69 \%$ & $95 \%$ & $76 \%$ \\
\hline & Elbow Flex Requirement Load & 8 & $97 \%$ & $97 \%$ & $100 \%$ & $97 \%$ \\
\hline \multirow{2}{*}{$\begin{array}{l}\text { 5th Percentile } \\
\text { Female Model }\end{array}$} & Wrist Flex Requirement Load & 17 & $42 \%$ & $42 \%$ & $80 \%$ & $83 \%$ \\
\hline & Elbow Flex Requirement Load & 8 & $95 \%$ & $95 \%$ & $99 \%$ & $98 \%$ \\
\hline \multirow{2}{*}{$\begin{array}{c}\text { Pilot Test Subject } \\
\text { Average }\end{array}$} & Wrist Flex Measured Load & 13.7 & - & - & - & - \\
\hline & Elbow Flex Measured Load & 14.7 & - & - & - & - \\
\hline
\end{tabular}

Variable joint selection as a confounding factor was not well addressed with the modeling package chosen. This requirement was identified as a confounding factor when multiple joints could provide the motion required by hardware designers. The model indicated a success rate of less than $50 \%$ for the loads required by the anthropometry of a $5^{\text {th }}$ percentile female. That is supported by subjective feedback from the human test subjects, who reported that this posture was uncomfortable and not how they would prefer to perform the task. It was observed that subjects could generate slightly more force at the dynamometer head when attempting to flex at the elbow rather than the wrist. Neither the model, nor the human testing seemed to reflect the system predicted by the strength requirements, where the wrist flexion strength should have been much higher than the elbow flexion strength. The wrist flexion strength requirement is likely much higher than experimental results due to a difference of posture, with strength requirements showing a braced forearm while the forearm was unsupported in this testing in order to combine wrist and elbow flexion. This makes the case for humanin-the-loop testing when hardware designers need to determine, out of several options, how a task should be done. 


\subsection{Braced Exertion Results}

Results from the braced exertion analysis are presented in Table 3. Percentages of the population with the strength to complete the task and average strength from the human test subjects are again presented below. 3DSSPP offered another metric here in the form of coefficient of friction necessary for the system to exist statically without slippage given the posture and forces on the body. Coefficient of friction is calculated as the ratio of the sum of horizontal forces to the sum of body weight and external vertical forces.

Table 3. Braced Exertion Results

\begin{tabular}{|c|c|c|c|c|c|c|c|c|c|}
\hline \multirow{2}{*}{$\begin{array}{c}\text { Model } \\
\text { Anthropometry }\end{array}$} & \multirow{2}{*}{ Posture } & \multirow{2}{*}{$\begin{array}{c}\text { Load at Right } \\
\text { Hand (Ibs) }\end{array}$} & \multirow{2}{*}{$\begin{array}{c}\text { Load at Left } \\
\text { Hand (Ibs) }\end{array}$} & \multirow{2}{*}{$\begin{array}{c}\text { Minimum \% } \\
\text { Accommodated }\end{array}$} & \multicolumn{3}{|c|}{$\%$ Accommodated at } & \multirow{2}{*}{ Balance } & \multirow{2}{*}{$\begin{array}{l}\text { Coefficient } \\
\text { of Friction }\end{array}$} \\
\hline & & & & & Shoulder & Elbow & Wrist & & \\
\hline \multirow{2}{*}{$\begin{array}{l}\text { 50th Percentile } \\
\text { Male }\end{array}$} & Unbraced & 24 & 0 & $99 \%$ & $99 \%$ & $100 \%$ & $100 \%$ & Acceptable & 0.382 \\
\hline & Braced & 24 & 22 & $99 \%$ & $99 \%$ & $100 \%$ & $100 \%$ & Acceptable & 0.494 \\
\hline \multirow{2}{*}{$\begin{array}{l}\text { 95th Percentile } \\
\text { Male }\end{array}$} & Unbraced & 24 & 0 & $99 \%$ & $99 \%$ & $100 \%$ & $100 \%$ & Acceptable & 0.253 \\
\hline & Braced & 24 & 22 & $99 \%$ & $99 \%$ & $100 \%$ & $100 \%$ & Acceptable & 0.326 \\
\hline \multirow{2}{*}{$\begin{array}{l}\text { 5th Percentile } \\
\text { Female }\end{array}$} & Unbraced & 24 & 0 & $90 \%$ & $90 \%$ & $100 \%$ & $100 \%$ & Unacceptable & -- \\
\hline & Braced & 24 & 22 & $90 \%$ & $90 \%$ & $100 \%$ & $100 \%$ & Acceptable & 0.518 \\
\hline \multirow{2}{*}{$\begin{array}{c}\text { Pilot Test Subject } \\
\text { Average }\end{array}$} & Unbraced & 28.8 & - & - & - & - & - & - & - \\
\hline & Braced & 49.5 & - & - & - & - & - & - & - \\
\hline
\end{tabular}

Bracing as a confounding factor was not well addressed by the analyzed modeling package, chiefly due to the limitations of the model's inputs and the complexity of the human system. 3DSSPP relies on externally applied forces and weight of the body to calculate joint torques, while the act of bracing creates a more complex load scenario than can be modeled with limited inputs. Human testing did indicate significant strength gains in the presence of bracing. This represents a conundrum for strength requirements, as bracing presents a possible means for increasing human strength applied into a system, but it also makes the system more difficult to address with even a robust set of strength requirement values. In general, strength gains due to bracing should not be counted on when protecting for the weakest crewmembers, but should be addressed when protecting hardware failure loads.

\subsection{Off-Nominal Exertion Results}

Results from the off-nominal exertion analysis are presented in Table 4 below. Percentages of the population with the strength to complete the task and average human test subject strength are again presented as labeled; for tasks performed in the nominal posture present in the strength requirements, and at an elevated posture more representative of actual hardware placement.

As a confounding factor to the deployment of strength requirements, the off-nominal exertion exercise was probably the most indicative of a common issue facing space vehicle design. Hardware and controls are more likely to be on the periphery of the habitable volume requiring reaches outside of the nominal postures for which strength requirements were created. A decrease in strength capacity by crewmembers at the limits of their reach could potentially result in a failure to actuate hardware that strength requirements would indicate should be operable when in a nominal posture. The 3DSSPP models showed a decrease in population accommodated ranging from $0 \%$ to $23 \%$ while the human test subjects showed a decrease in strength capabilities between 
$9 \%$ and $21 \%$ in the elevated, off-nominal posture (Table 5). This suggests that strength modeling is best suited to accounting for changes that only affect the physics of the system, such as off-nominal reach zones, but is less effective when there is a cognitive component, such as a choice of joint selection or complex bracing scenario.

Table 4. Off Nominal Exertions

\begin{tabular}{|c|c|c|c|c|c|c|}
\hline \multirow{2}{*}{$\begin{array}{l}\text { Model Posture \& } \\
\text { Anthropometry }\end{array}$} & \multirow[b]{2}{*}{ Hand Load } & \multirow{2}{*}{$\begin{array}{c}\text { Right Hand } \\
\text { Load (lbs) }\end{array}$} & \multirow{2}{*}{$\begin{array}{c}\text { Minimum \% } \\
\text { Accommodated }\end{array}$} & \multicolumn{3}{|c|}{$\%$ Accommodated at } \\
\hline & & & & Shoulder & Elbow & Wrist \\
\hline \multirow{4}{*}{$\begin{array}{l}\text { Nominal Elevation } \\
\text { 50th Percentile Male }\end{array}$} & Push & 22 & $98 \%$ & $98 \%$ & $100 \%$ & $100 \%$ \\
\hline & Medial & 13 & $94 \%$ & $100 \%$ & $100 \%$ & $94 \%$ \\
\hline & Pull & 24 & $99 \%$ & $99 \%$ & $100 \%$ & $100 \%$ \\
\hline & Lateral & 8 & $97 \%$ & $100 \%$ & $100 \%$ & $97 \%$ \\
\hline \multirow{4}{*}{$\begin{array}{c}\text { High Elevation } \\
\text { 50th Percentile Male }\end{array}$} & Push & 22 & $87 \%$ & $100 \%$ & $98 \%$ & $87 \%$ \\
\hline & Medial & 13 & $94 \%$ & $100 \%$ & $100 \%$ & $94 \%$ \\
\hline & Pull & 24 & $88 \%$ & $100 \%$ & $99 \%$ & $88 \%$ \\
\hline & Lateral & 8 & $97 \%$ & $100 \%$ & $100 \%$ & $97 \%$ \\
\hline \multirow{4}{*}{$\begin{array}{l}\text { Nominal Elevation } \\
\text { 95th Percentile Male }\end{array}$} & Push & 22 & $95 \%$ & $95 \%$ & $100 \%$ & $100 \%$ \\
\hline & Medial & 13 & $92 \%$ & $100 \%$ & $100 \%$ & $92 \%$ \\
\hline & Pull & 24 & $99 \%$ & $99 \%$ & $100 \%$ & $100 \%$ \\
\hline & Lateral & 8 & $97 \%$ & $100 \%$ & $100 \%$ & $97 \%$ \\
\hline \multirow{4}{*}{$\begin{array}{c}\text { High Elevation } \\
\text { 95th Percentile Male }\end{array}$} & Push & 22 & $85 \%$ & $100 \%$ & $98 \%$ & $85 \%$ \\
\hline & Medial & 13 & $92 \%$ & $100 \%$ & $100 \%$ & $92 \%$ \\
\hline & Pull & 24 & $84 \%$ & $99 \%$ & $99 \%$ & $84 \%$ \\
\hline & Lateral & 8 & $97 \%$ & $100 \%$ & $100 \%$ & $97 \%$ \\
\hline \multirow{4}{*}{$\begin{array}{l}\text { Nominal Elevation } \\
\text { 5th Percentile Female }\end{array}$} & Push & 22 & $83 \%$ & $83 \%$ & $100 \%$ & $100 \%$ \\
\hline & Medial & 13 & $85 \%$ & $85 \%$ & $100 \%$ & $94 \%$ \\
\hline & Pull & 24 & $90 \%$ & $90 \%$ & $100 \%$ & $100 \%$ \\
\hline & Lateral & 8 & $97 \%$ & $99 \%$ & $100 \%$ & $97 \%$ \\
\hline \multirow{4}{*}{$\begin{array}{l}\text { High Elevation } \\
\text { 5th Percentile Female }\end{array}$} & Push & 22 & $60 \%$ & $99 \%$ & $60 \%$ & $85 \%$ \\
\hline & Medial & 13 & $85 \%$ & $85 \%$ & $100 \%$ & $94 \%$ \\
\hline & Pull & 24 & $87 \%$ & $100 \%$ & $94 \%$ & $87 \%$ \\
\hline & Lateral & 8 & $97 \%$ & $98 \%$ & $100 \%$ & $97 \%$ \\
\hline \multirow{4}{*}{$\begin{array}{c}\text { Nominal Elevation } \\
\text { Pilot Test Subject } \\
\text { Average }\end{array}$} & Push & 21.6 & - & - & - & - \\
\hline & Medial & 16.2 & - & - & - & - \\
\hline & Pull & 32.1 & - & - & - & - \\
\hline & Lateral & 18.3 & - & - & - & - \\
\hline \multirow{4}{*}{$\begin{array}{l}\text { High Elevation Pilot } \\
\text { Test Subject Average }\end{array}$} & Push & 19.7 & - & - & - & - \\
\hline & Medial & 13.3 & - & - & - & - \\
\hline & Pull & 25.5 & - & - & - & - \\
\hline & Lateral & 14.6 & - & - & - & - \\
\hline
\end{tabular}


Table 5. Percent change in arm strength by arm posture

\begin{tabular}{|c|c|c|}
\hline $\begin{array}{l}\text { Model Posture \& } \\
\text { Anthropometry }\end{array}$ & $\begin{array}{l}\text { Hand } \\
\text { Load }\end{array}$ & $\begin{array}{c}\text { Change in } \\
\text { Reported } \\
\text { Strength }\end{array}$ \\
\hline \multirow{4}{*}{$\begin{array}{l}\text { Delta Accommodation - } \\
\text { 50th Percentile Male }\end{array}$} & Push & $-11 \%$ \\
\hline & Medial & $0 \%$ \\
\hline & Pull & $-11 \%$ \\
\hline & Lateral & $0 \%$ \\
\hline \multirow{4}{*}{$\begin{array}{l}\text { Delta Accommodation - } \\
\text { 95th Percentile Male }\end{array}$} & Push & $-10 \%$ \\
\hline & Medial & $0 \%$ \\
\hline & Pull & $-15 \%$ \\
\hline & Lateral & $0 \%$ \\
\hline \multirow{4}{*}{$\begin{array}{l}\text { Delta Accommodation - } \\
\text { 5th Percentile Female }\end{array}$} & Push & $-23 \%$ \\
\hline & Medial & $0 \%$ \\
\hline & Pull & $-3 \%$ \\
\hline & Lateral & $0 \%$ \\
\hline \multirow{4}{*}{$\begin{array}{l}\text { Delta Strength - Pilot } \\
\text { Test Subject Average }\end{array}$} & Push & $-9 \%$ \\
\hline & Medial & $-18 \%$ \\
\hline & Pull & $-20 \%$ \\
\hline & Lateral & $-20 \%$ \\
\hline
\end{tabular}

\subsection{Additional Analyses}

Human modeling and human testing were applied to three commonly occurring situations where strength requirements did not map well to operational realities. The human modeling package that was utilized, 3DSSPP, cannot definitively state if a task passes or fails due to the different objective of the software, but it can give some insight as to whether or not a task is likely to be problematic for the weakest potential crewmember to complete. Human testing can offer numerous useful insights regarding task completion, but it is difficult to state definitively whether a task protects for the weakest crewmember when testing with a finite number of test subjects.

While strength requirements are a ubiquitous part of space human factors, their practical application to hardware design has long been a source of confusion. This manuscript sought to clear up some common questions about the application of NASA's strength requirements to various confounding factors. The Human Integration Design Handbook [6] mentions numerous factors to consider when using human-centered design; however, it does not describe actionable advice to answer questions about specific loading profiles. If the loading scenario is decomposed into its most simplistic form and it still does not perfectly fit the strength requirement tables, the primary remaining options to determine if the loading profile is acceptable involves either human modeling or human testing. The results of this study suggests that human-in-the-loop testing be involved for all verification scenarios of space hardware accommodation, while human modeling may offer some insight and cost savings early in the design process. 


\section{Conclusions}

This study sought to demonstrate potential approaches for strength requirement usage. The examples included here are not fully comprehensive. The presence of a space suit adds a significant confounding factor that was not addressed in this manuscript. Part II of this study aims to better understand the influence of space suits on subject strength, include additional human testing, and expand the depth of data included in the strength database. When in doubt of how to use the strength requirement tables, a safe approach often involves asking the subject matter experts for feedback.

Strength requirements are important for human-centric design, but difficult to define for every conceivable operation. When a new operation or piece of hardware is being designed that does not map well to strength requirements, human modeling and human testing remain the two best options to determine if the required loads can be accommodated. Modeling offers several benefits in terms of cost and speed of analysis but is often constrained by the assumptions and variables of the modeling program. Human testing typically offers the most flexibility for test setup, though test hardware can be expensive to maintain. Future work is necessary to expand findings for other complex loading scenarios including the influence of spacesuits on the application of strength requirements.

\section{$5 \quad$ References}

1. Human System Integration Requirement Document (Rev E), Constellation Program 70024. National Aeronautics and Space Administration (2010)

2. ISS Crew Transportation Services Requirements Document (Rev C), Commercial Crew Program 1130. National Aeronautics and Space Administration (2013)

3. University of Michigan Center for Ergonomics, 3D Static Strength Prediction Program User's Manual. Retrieved from http://umich.edu/ ioe/3DSSPP/Manual_606.pdf (2014)

4. Kroemer, K.H.E., Kroemer, H.B., and Kroemer-Elbert, K.E.: Ergonomics: How to Design for Ease and Efficiency (2nd. ed.). Prentice Hall, Upper Saddle River, NJ: (2001)

5. Chaffin, D.B., Andersson, G.B., Martin, B.J.: Occupational Biomechanics ( $3^{\text {rd }}$ ed). John Wiley and Sons, Inc, New York (1999)

6. Human Integration Design Handbook, NASA/SP 2010-3407. National Aeronautics and Space Administration (2010) 